\title{
Habitat segregation and mosaic sympatry of the two species of manta ray in the Indian and Pacific Oceans: Manta alfredi and M. birostris-CORRIGENDUM
}

TOM KASHIWAGI, ANDREA D. MARSHALL, MICHAEL B. BENNETT AND JENNIFER R. OVENDEN

doi:10.1017/S1755267211000479, Published by Cambridge University Press, 10 June 2011.

The authors regret that the table in a Appendix of this article (Kashiwagi et al., 2011) contained errors. The number of records for Manta alfredi and Manta birostris for the site 'Chichijima' (Locality: Ogasawara, Japan) are '-' (i.e. zero) and '24', respectively (instead of 24 and -). The number of records for Manta alfredi and Manta birostris for the site 'Hahajima' are '-' and ' 18 ', respectively (instead of 28 and -).

REFERENCE

Kashiwagi T., Marshall A.D., Bennett M.B. and Ovenden J.R. (2011) Habitat segregation and mosaic sympatry of the two species of manta ray in the Indian and Pacific Oceans: Manta alfredi and M. birostris. Marine Biodiversity Records, 4, e53 doi:10.1017/S1755267211000479. 